\title{
'Conversion' from ulcerative colitis to Crohn's disease associated with corticosteroid treatment
}

\author{
A D Dwarakanath, J Nash, J M Rhodes
}

\begin{abstract}
A man who was a non-smoker presented with clinical, histological, and radiological features typical of distal ulcerative colitis. Prolonged treatment with corticosteroids was associated with the development of numerous granulomata, stricturing, and perianal disease. It is speculated that the immunosuppression associated with the corticosteroid treatment may have induced a change from ulcerative colitis to Crohn's disease of the colon. This case report lends support to the hypothesis that these conditions may just represent different forms of a continuum of inflammatory bowel disease.

(Gut 1994; 35: 1141-1144)
\end{abstract}

Most clinicians view ulcerative colitis and Crohn's disease as separate entities. Although, up to $15 \%$ of cases may be difficult to categorise and may be termed indeterminate colitis, ${ }^{12}$ the presence of granulomata is usually regarded as strongly suggestive of Crohn's disease. If this principle is rigidly adhered to a zero incidence of granulomata in ulcerative colitis results, although some authors accept that occasional granulomata can be found in $24 \%$ of patients with ulcerative colitis. ${ }^{34}$ The wide use of the granuloma as the cornerstone of diagnosis in Crohn's disease often results in the diagnosis being changed from ulcerative colitis to Crohn's disease with the assumption that the previous diagnosis was mistaken.

Here we describe a patient who presented with typical clinical, radiological, and histological features of ulcerative colitis who developed florid granulomatous colitis with typical

Departments of Medicine

A D Dwarakanath

$J M$ Rhodes

and Pathology,

University of

Liverpool, Liverpool

J Nash

Correspondence to: Dr A D Dwarakanath, Dr A D Dwarakanath, Department of Medicine, University of Liverpool,

PO Box 147.
L69 3BX.

Accepted for publication 29 November 1993
Figure 1: Sigmoid colon biopsy specimen at presentation showing typical features of ulcerative colitis goblet cell depletion, acute inflammatory cell infiltrate, mucosal ulceration, and crypt abscess formation. features of Crohn's disease when treated longterm with high dose corticosteroids.

\section{Case report}

A 24 year old non-smoking man, with a maternal aunt with ulcerative colitis, presented with a two month history of increased bowel frequency, five to eight times per day, with blood and mucus from the rectum and four $\mathrm{kg}$ weight loss. There were no systemic manifestations of inflammatory bowel disease. Abdominal examination was unremarkable, however, rigid sigmoidoscopy showed a severe proctitis. A biopsy specimen at this time showed an increased mixed inflammatory cell infiltrate in the lamina propria with infiltration of glandular epithelium by polymorphs although few crypt abscesses were seen. There was severe distortion of glandular architecture with appreciable mucin depletion. Paneth cells were identified. The appearances were consistent with moderately severe active ulcerative colitis (Fig 1). His haemoglobin was $14 \cdot 1 \mathrm{~g} / \mathrm{dl}$, erythrocyte sedimentation rate (ESR) $7 \mathrm{~mm}$ in first hour, and serum iron $7 \mu \mathrm{mol} / 1$ (normal range $13-32 \mu \mathrm{mol} / 1$ ).

He was given rectal corticosteroids, sulphasalazine, and ferrous sulphate. A subsequent barium enema showed confluent fine irregularity of the mucosa of the rectum, sigmoid, and distal descending colon (Fig 2). The rest of the colon was normal, hence a diagnosis of distal ulcerative colitis was made.

Over the next $3 \frac{1}{2}$ years his disease was treated with a combination of sulphasalazine and rectal steroids; one flare up during this period settled spontaneously. A further barium enema during this period did not show any extension of his disease.

Fifty one months after diagnosis he was admitted with increased bowel frequency, rectal bleeding, and night sweats. Abdominal examination was unremarkable. Investigations showed a haemoglobin of $9 \mathrm{~g} / \mathrm{dl}$ and an ESR of $80 \mathrm{~mm}$ in the first hour. At colonoscopy the rectum and sigmoid colon were diseased with granularity, contact haemorrhage, and pseudopolyps. Histological examination confirmed active ulcerative proctitis; these biopsies together with the previous biopsies giving a total of 10 biopsies supporting a diagnosis of ulcerative colitis. He was given intravenous prednisolone $40 \mathrm{mg}$ once daily for 12 days and subsequently oral prednisolone $40 \mathrm{mg}$ once daily together with mesalazine $400 \mathrm{mg}$ thrice daily and ferrous sulphate. He continued to improve over the next few months, but failed to go into complete remission and continued 


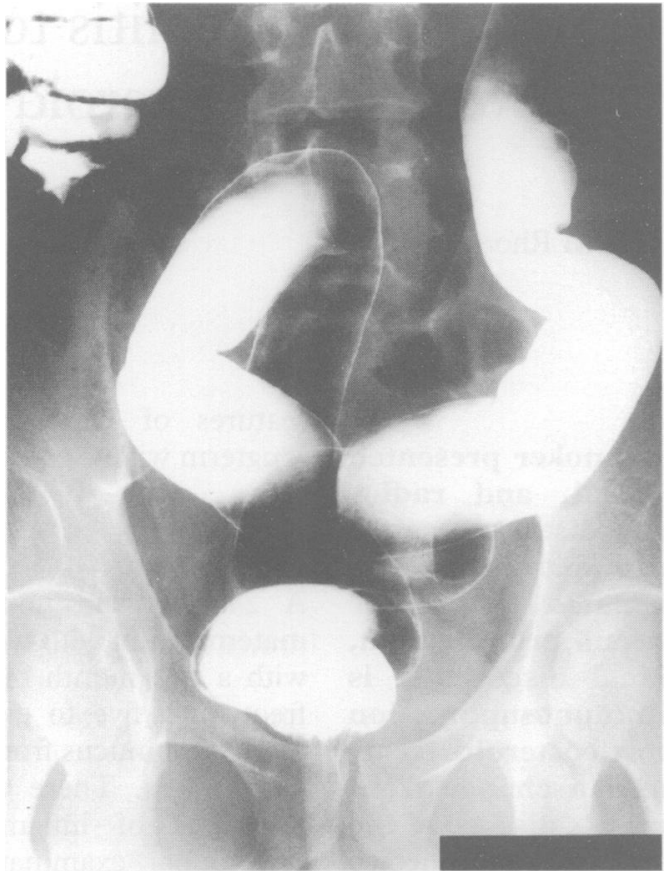

Figure 2: Barium enema at initial presentation showing confluent fine ulceration of the rectum, sigmoid, and dista descending colon in keeping with the diagnosis of ulcerative colitis.

receiving corticosteroid treatment in varying doses (Fig 3).

Nine months later a further flare up of his colitis occurred requiring inpatient care, his ESR being $57 \mathrm{~mm}$ in the first hour on admission. A colonoscopy at this time showed a severe colitis up to $45 \mathrm{~cm}$, with the rest of the colon being normal. Ten biopsy specimens were taken of which the distal 7 (from the rectum, sigmoid, and descending colon) all showed multiple granulomata. Oral prednisolone was withdrawn and rectal corticosteroids introduced.

He relapsed shortly after discharge, and was given oral prednisolone for the next 24 months, with the dose not being reduced below $12.5 \mathrm{mg}$ daily. During this period two further sigmoidoscopies showed an active proctitis, four biopsy specimens showed granulomata (Fig 4). A small bowel enema was normal but he had developed typical perianal Crohn's disease with fistula formation.

He had become Cushingoid in appearance and was referred for advice about his medical treatment. $\mathrm{He}$ was given metronidazole

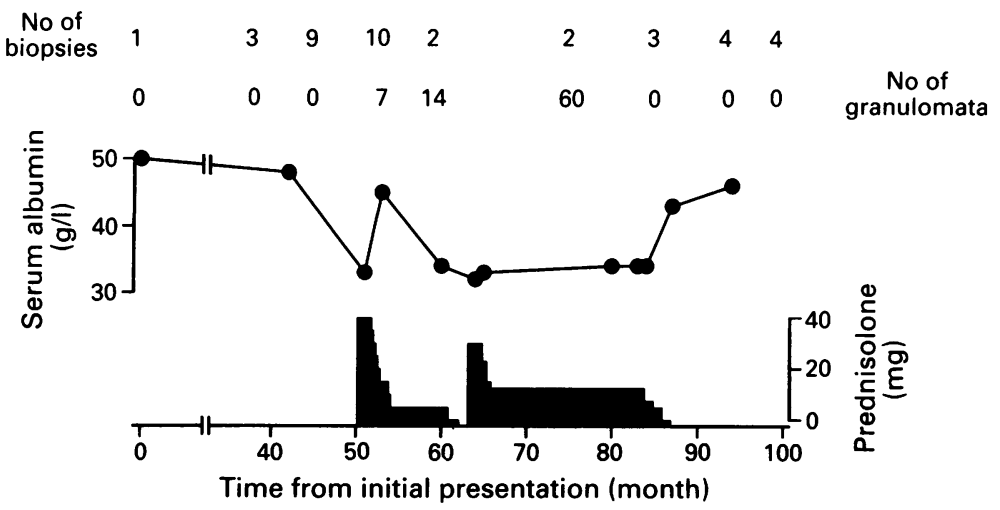

Figure 3: A comparison of corticosteroid dose, biopsy number, granulomata number, and serum albumin showing the striking increase in granulomata coincidental with corticosteroid treatment.
$400 \mathrm{mg}$ thrice daily, vitamin C $500 \mathrm{mg}$ daily, bismuth subsalicylate enemas, ${ }^{5}$ and enteric feeding with Triosorbon ${ }^{6}$; with his corticosteroids being withdrawn over a 12 week period. His general condition then improved considerably serum albumin rising from 34 to $43 \mathrm{~g} / \mathrm{l}$ weight from 47 to $53 \mathrm{~kg}$ while his colitis remained distal and only moderately active.

Two years after corticosteroid treatment had finished he remained systemically well although continued to have intermittent diarrhoea. Colonoscopy showed benign stricturing in the sigmoid colon, which responded to balloon dilation. Eleven biopsy specimens taken at five colonoscopies did not show any granulomata, the histological appearances again being typical of ulcerative colitis although perianal disease persists.

\section{Discussion}

This case illustrates a patient with typical clinical, radiological, and histological features of ulcerative colitis, who subsequently developed granulomatous colitis with stricturing and perianal disease while receiving a protracted course of corticosteroid treatment. When the corticosteroids were withdrawn, 11 subsequent biopsy specimens did not show granulomata and stricturing resolved (albeit aided by balloon dilatation).

The question of whether inflammatory bowel disease is one disease or two ${ }^{7}$ remains valid while the aetiology is unknown. The arguments over diagnosis are often circular: Crohn's disease is characterised by granulomata therefore colonic granulomata means Crohn's disease, this probably results in a diagnosis commonly being changed from ulcerative colitis to Crohn's disease when the first granuloma is found but almost never from Crohn's disease to ulcerative colitis. This perhaps might explain why, if both diseases represent a continuum of one disease, there are no cases in published works of 'transformation' form Crohn's disease to ulcerative colitis.

The well reported families within which some subjects have ulcerative colitis and others have Crohn's disease, ${ }^{8}$ provide perhaps the strongest line of evidence in favour of the conditions

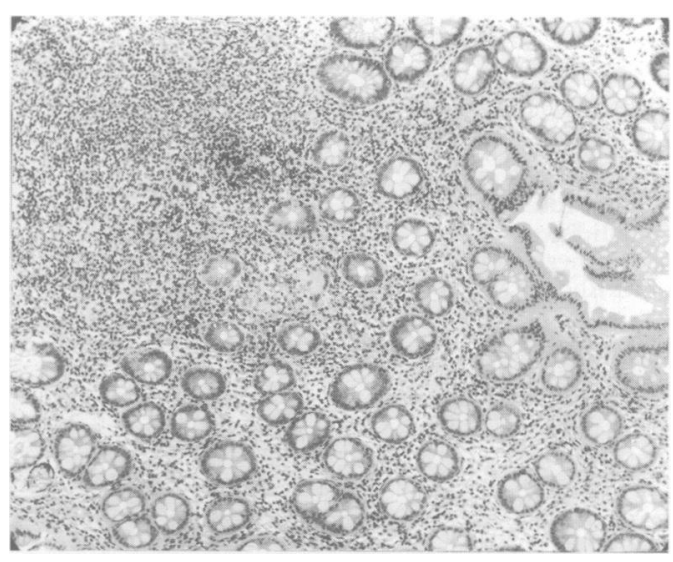

Figure 4: Colonoscopic biopsy specimen after 12 months corticosteroid treatment showing typical features of Crohn's disease with goblet cell mucin retention and granulomatous inflammation. 
being part of a single spectrum of disease. Studies in twins have shown coincidence for Crohn's disease to be very much more likely than for ulcerative colitis, ${ }^{9}$ this being higher for monozygotic twins than dizygotic twins. This suggests an important genetic component to the diseases, with various environmental factors being important in the differentiation into Crohn's disease and ulcerative colitis. Studies have shown that patients with ulcerative colitis are probably non-smokers, either former or lifelong; in contrast with Crohn's disease patients who are more likely to be smokers. ${ }^{10}$ When inflammatory bowel disease patients are taken as a whole, however, their smoking habits are similar to controls and this has been argued as evidence for one disease with the presence or absence of smoking determining the nature of the inflammatory process. It is plausible that corticosteroid treatment could be another factor in the development of features associated with Crohn's disease.

Proponents of an infective aetiology for Crohn's disease could argue that corticosteroid treatment may depress the host immune response and permit exacerbation of the underlying infection. This is well known to occur if tuberculosis is inadvertently treated by corticosteroids, however, tuberculosis in the immunosuppressed patient is usually associated with a paucity of granulomata. ${ }^{1112}$

Alternatively the granulomata might be the result of corticosteroid induced defects in phagocytic function without any specific infective organism. Several authors ${ }^{13-15}$ have shown decreased function of human polymorphonuclear leucocytes when treated, in vitro, with corticosteroids. In vitro studies show that corticosteroids reduce the function of neutrophils against Pseudomonas aeruginosa resulting in incomplete phagocytosis, lack of vacuole coalescence, and minimal disruption of bacterial cell walls. ${ }^{13}$ Neutrophil function measured by the release of neutrophil cobalamin binding protein, which is exclusively located in the neutrophil secondary granules, is also inhibited by exposure to corticosteroids. ${ }^{14}$ In vitro, neutrophil mediated antibody dependent cell cytotoxicity has been shown to be inhibited by hydrocortisone, methyl prednisolone, and dexamethasone ${ }^{15}$ as has neutrophil chemotaxis. ${ }^{16}$

There are two rare conditions, malakoplakia and chronic granulomatous disease, which result from defects in phagocytic function and in which granulomatous colitis may occur. Malakoplakia is a granulomatous disease, occurring typically in the genitourinary tract, but which can cause a colitis that closely mimics Crohn's disease. ${ }^{17} 18$ In this condition there is a failure of phagocytes to kill bacteria, related to a low cGMP/cAMP ratio. ${ }^{19}$ Similarly in chronic granulomatous disease where there are inherited, autosomal or X linked, neutrophil defects that impair the ability to kill ingested bacteria, colitis may again occur that mimics Crohn's disease.

There is considerable evidence that phagocytic function may be impaired in Crohn's disease, even in the absence of corticosteroid treatment; this includes a lower level of polymorph oxidative metabolism than those of treated patients and controls, ${ }^{20-22}$ decreased sensitivity and peak response to the major complement derived chemotactic factor C5a by polymorphonuclear leucocytes, ${ }^{23}$ decreased stimulated migration, increased adhesiveness, and decreased electrophoretic mobility. ${ }^{24}$ Complement dysfunction and inhibitory factors of neutrophil chemotaxis are also described. 2526

In the case reported here the time course of the appearance and subsequent disappearance of granulomata raises the possibility that decreased polymorph function caused by corticosteroid treatment may have provoked the development of granulomata. This could be a further reason, apart from its lack of efficacy, ${ }^{27}$ ${ }^{28}$ why maintenance corticosteroid treatment should be avoided in ulcerative colitis. This case also provides further evidence for the view that ulcerative colitis and Crohn's disease may represent a continuing spectrum of inflammatory bowel disease.

ADD is supported by a grant from the British Digestive Foundation/National Association for Colitis and Crohn's disease.

1 Price AB. Overlap in the spectrum of non-specific inflammatory bowel disease 'Colitis indeterminate'. $\mathcal{F}$ Clin Pathol 1978; 31: 567-77

2 Lee KS, Medline A, Shockey S. Indeterminate colitis in the spectrum of inflammatory bowel disease. Arch Pathol Lab Med 1979; 103: 173-6.

3 Morson BC, Dawson IMP. Inflammatory disorders. In: Gastrointestinal pathology 2nd ed. Oxford: Blackwell Scientific 1979: 512-74.

4 Schacter H, Goldstein MJ, Rappaport H, Fennessy MB, Kirsner JB. Ulcerative and granulomatous colitis: validity of different $841-51$.

5 Ryder SD, Walker RJ, Jones H, Rhodes JM. Rectal bismuth subsalicylate as therapy for ulcerative colitis. Aliment Pharmacol Therap 1990; 4: 333-8.

6 Raouf A, Hildrey V, Daniel J, Walker RJ, Krasner N, Elias $\mathrm{E}$, et al. Enteral feeding as sole therapy for Crohn's disease: a controlled trial of whole protein versus aminoacid based feed and a case study of dietary challenge. Gut 1991; 32: 702-7.

7 Hodgson HJF. One disease or two? In: Inflammatory bowel diseases. Allan RN, Keighley MRB, Alexander-Williams J, Hawkins C, eds. 2nd ed. London: Churchill Livingstone, 1990: 121-6.

8 Mons'en V, Brostrom O, Nordendrall B, Sorstad J, Hellers G. Prevalence of inflammatory bowel disease among relatives of patients with ulcerative colitis. Scand $f$ relatives of patients with ulcer
Gastroenterol 1987; 22: 214-18.

9 Purrmann J, Bertrams J, Borchard F. Monozygotic triplets with Crohn's disease of the colon. Gastroenterology 1986; 91: 1553-9.

10 Logan RF, Edmond M, Somerville KW, Langman MJ, Smoking and ulcerative colitis. BMF 1984; 288: 751-3.

11 O'Brien JR. Non-reactive tuberculosis. f Clin Pathol 1954; 7: $216-25$.

12 Nambuya A, Sewankambo N, Mugerwa J, Goodgame R, Lucas S. Tuberculous lymphadenitis associated with human immunodeficiency virus in Uganda. $\mathcal{F}$ Clin Pathol 1988; 41: 93-6.

13 Baltch AL, Hammer MC, Smith RP, Bishop MB, Sutphen NT, Egy MA, et al. Comparison of the effect of three adrenal corticosteroids on human granulocyte function adrenal corticosteroids on human granulocyte function against

14 Davies J, Sheppard K, Fletcher J. Inhibition of human neutrophil secondary granule discharge by antiinflammatory agents. Inflammation 1984; 8: 343-51.

15 Capsoni F, Meroni PL, Zocchi MR, Plebani AM, Vezio $M$. Effect of corticosteroids on neutrophil function: inhibition of antibody-dependent cell mediated cytotoxicity. $\mathcal{f}$ Immunopharmacol 1983 5: 217-30.

16 Rhodes JM, Jewell DP. Inhibition of leucocyte motility by drugs used in inflammatory bowel disease. Gut 1981; 22: 642-7.

17 Gonzalez-Angulo A, Corral E, Garcia-Torres R, Quijano M, Malakoplakia of the colon. Gastroenterology 1965; 48: 383-7.

18 Terner J, Lattes R. Malakoplakia of the colon. Fed Proc 1963 ; 22: 572-4.

19 Wiggelinkhuizen J, Mills A, Emms M. Bilateral renal malakoplakia in infancy. Child Nephrol Urol 1988-89; 9: 104-5. 
20 Verspaget HW, Miermont-Ooms MA, Weterman IT, Pena AS. Partial defect of neutrophil oxidative metabolism in AS. Partial defect of neutrophil oxida
Crohn's disease. Gut 1984; 25: 849-53.

21 Verspaget HW, Elmgreen J, Weterman IT, Pena AS, Rilis $P$, Lamers CB. Impaired activation of the neutrophil oxidative metabolism in chronic inflammatory bowel disease. Scand f Gastroenterol 1986; 21: 1124-30. 22 Verspaget HW, Pena AS, Weterman IT, Lamers CB. ulcerative colitis identified by decreased oxidative metabolism and low superoxide dismutase content. Gut 1988; 29: 223-8.

23 Elmgreen J. Subnormal activation of neutrophils in inflammatory bowel disease. Neutrophil chemotaxis to complematory bowel disease. Neutrophil chemotaxis to comple-

24 Kirk AP, Cason J, Fordham JN, Brown KA, Goddard DH,
Holborow EJ, et al. Polymorphonuclear leucocyte function in ulcerative colitis and Crohn's disease. Dig Dis Sci 1983; 28: $236-48$.

25 Rhodes JM,. Potter BJ, Brown DJ, Jewell DP. Serum inhibition of leucocyte chemotaxis in Crohn's disease and ulcerative colitis. Gastroenterology 1983; 82: 1327-34

26 D'Amelio R, Pallone F, Le-Moli S, Pontesilli O, Ricci R, Montano $\mathrm{S}$, et al. Humoral inhibition of neutrophil chemotaxis in Crohn's disease. Scand f Immunol 1985; 22: 597-602.

27 Truelove SC, Witts LJ. Cortisone and corticotrophin in ulcerative colitis. $B M \mathcal{F} 1959 ; 1$ : 387-94.

28 Lennard-Jones JE, Misiewicz JJ, Connell AM, Baron JH, Jones FA. Prednisone as maintenance treatment for ulcerative colitis in remission. Lancet $1965 \mathrm{i}: 188-89$. 